\title{
Inappropriate Prescribing to Elderly Patients in an Internal Medicine Ward
}

\section{Prescrição Inapropriada em Idosos numa Enfermaria de Medicina Interna}

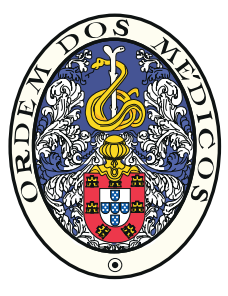

Joana URZAL $\otimes^{1}$, Ana Bárbara PEDRO ${ }^{1}$, Inês Ferraz de OLIVEIRA ${ }^{1}$, Inês ROMERO ${ }^{1}$, Miguel ACHEGA 1 , Iuri CORREIA ${ }^{1}$, Fernando ALDOMIRO' ${ }^{1}$, João AUGUSTO ${ }^{2}$

Acta Med Port 2019 Feb;32(2):141-148 - https://doi.org/10.20344/amp.10683

\section{ABSTRACT}

Introduction: Polypharmacy is often observed in elderly patients and is associated with an increased risk of adverse drug reactions, side effects and interactions. Clinicians should be alert to inappropriate drug prescribing and reduce polypharmacy.

Material and Methods: Observational, longitudinal, retrospective and descriptive study in an internal medicine ward in a Portuguese hospital. Polypharmacy was defined as the use of five or more different medicines. The purpose of this study was to describe the prevalence of polypharmacy and inappropriate prescribing at admission and discharge in an internal medicine ward, according to deprescribing.org guidelines/algorithms. A total of 838 consecutive patients were admitted between January and July 2017. All patients were aged under 65 years old, and those who died before discharge were excluded. Patients' medications were reviewed from a medical database at hospital admission and discharge. We examined whether patients were taking anticoagulants, proton pump inhibitors, benzodiazepines, antipsychotics and/or antihyperglycemic medication.

Results: A total of 483 patients were included, mean age was $79.2 \pm 8.0$ years, and $42 \%$ of patients were male. Median number of medications at admission and discharge was six. Polypharmacy was present in more than $70 \%$ of admitted patients. Proton pump inhibitors were the most common inappropriate prescription at discharge $(17.2 \%)$.

Discussion: This study demonstrated a low use of inappropriate medicine $(11.2 \%-17.2 \%)$ in older people discharged from hospital, when compared to other studies.

Conclusion: Our study shows that polypharmacy is present in more than $70 \%$ of elderly admitted patients. Nevertheless, the drug inappropriateness rate was not significantly affected by polypharmacy at both admission and discharge, being overall lower than published data.

Keywords: Aged; Deprescriptions; Inappropriate Prescribing; Polypharmacy; Portugal

\section{RESUMO}

Introdução: A polimedicação é observada nos doentes idosos e está associada a um maior risco de reações adversas, efeitos secundários e interações. Os clínicos devem atentos à prescrição inapropriada e à redução da polimedicação.

Material e Métodos: Estudo observacional, longitudinal, retrospetivo e descritivo, realizado numa enfermaria de medicina interna num hospital português. Definimos a polimedicação como o uso de cinco ou mais medicamentos. O objetivo foi descrever a prevalência da polimedicação e a prescrição inapropriada, na admissão e alta, de acordo com as guidelines/algoritmos definidos em deprescribing. org. Admitimos 838 doentes entre janeiro e julho de 2017. Excluímos todos aqueles com idade inferior a 65 anos e óbitos. A medicação dos doentes foi revista a partir da base de dados hospitalar, à admissão e à data de alta. Examinámos se os doentes estavam a tomar anticoagulantes, inibidores da bomba de protões, benzodiazepinas, antipsicóticos e/ou anti hiperglicémicos.

Resultados: Incluímos 483 doentes, com média de idade de 79,2 $\pm 8,0$ anos, e $42 \%$ dos quais eram homens. A mediana da medicação à admissão e à alta foi seis. A polimedicação estava presente em mais de $70 \%$ dos doentes admitidos. Os inibidores da bomba de protões foram a classe mais inapropriadamente prescrita à data de alta $(17,2 \%)$.

Discussão: Demonstrámos um uso reduzido de fármacos inapropriados $(11,2 \%-17,2 \%)$ nos idosos, à alta hospitalar, quando comparado com outros estudos.

Conclusão: Demonstrámos que a polimedicação estava presente em mais de $70 \%$ dos idosos admitidos. Contudo, a taxa de prescrição inapropriada não afetou significativamente a polimedicação na admissão e na alta, sendo inferior aos dados publicados.

Palavras-chave: Desprescrições; Idoso; Polimedicação; Portugal; Prescrição Inadequada

\section{INTRODUCTION}

Mean life expectancy is increasing worldwide due to scientific developments and better disease prevention and treatment. Portugal is currently the fifth leading country in Europe in terms of life expectancy, with a 2016 registered ageing index of $148.7 \% .^{1}$ Older people develop more chronic conditions such as arterial hypertension (HTN), cardiac failure, diabetes, dyslipidemia, renal failure, sleeping disorders, neurologic diseases and cancer. Consequently, elderly people require multiple medications. ${ }^{2,3}$
The term polypharmacy comes from two Greek root words: poly, meaning many, and pharmakeia meaning medicines or drugs. Polypharmacy is defined by the World Health Organization as "the administration of many drugs at the same time or the administration of an excessive number of drugs". ${ }^{4}$ This definition is not clear as it does not refer to a specific number, neither indicates the temporal condition under which polypharmacy is administered simultaneously. ${ }^{5}$ Currently, there is no consensus on the medication

\footnotetext{
1. Departamento de Medicina Interna. Hospital Professor Doutor Fernando Fonseca. Amadora. Portugal.

2. Departamento de Cardiologia. Hospital Professor Doutor Fernando Fonseca. Amadora. Portugal.

$\triangle$ Autor correspondente: Joana Urzal. joana.urzal@hff.min-saude.pt

Recebido: 17 de abril de 2018 - Aceite: 28 de agosto de 2018 | Copyright @ Ordem dos Médicos 2019
} 
threshold defining polypharmacy. ${ }^{6,7}$ Therefore, in this study we defined polypharmacy if a patient was taking five or more medications, in order to compare with other studies. The notion of polypharmacy is often confused with inappropriate prescription. ${ }^{8}$

Potentially inappropriate medications (PIMs) are defined as drugs with ineffectiveness or high risk-benefit ratio. However, the high prevalence of PIMs should not be only attributed to inappropriate prescribing. ${ }^{9,10}$ Use of PIMs has been correlated with worse outcomes for the patient, including an increased risk of adverse drug reactions (ADRs), side effects, interactions, hospitalisation and mortality. ${ }^{11}$ ADRs can cause confusion, delirium, falls, hip fractures and a significant proportion of potential emergency room visits and hospitalisations, which could be avoided. ${ }^{12}$ The elderly population, due to their age and chronic conditions, may respond differently to drug or experience more severe ADRs. ${ }^{13}$ This can be explained by different pharmacokinetic and pharmacodynamic characteristics that take place later in life and can significantly contribute to enhanced drug related morbidity and mortality. ${ }^{14}$

Polypharmacy might be a serious public health problem concerning medicine's direct and indirect costs from drugrelated morbidity. ${ }^{15}$ Rational drug discontinuation in older adults is a logical approach to mitigate polypharmacy.

Deprescribing is an active review process that prompts the physician to consider which medications have lost their advantage in the risk-benefit trade-off, especially in patients with changing goals of care or limited life expectancy. ${ }^{16}$

There is a lack of data regarding the prevalence of polypharmacy in people over 65 years old in Portugal. There are some studies referring a polypharmacy prevalence of $18.8 \%,{ }^{17} 63.3 \%,{ }^{18} 64.8 \%{ }^{19}$ in a same day center, in two healthcare centers and $4^{\text {th }}$ National Health Survey, respectively. The prevalence of polypharmacy in the elderly population in other countries varies widely, ranging from $21 \%$ in Australia, ${ }^{20} 40 \%$ in Sweden, ${ }^{21} 63 \%$ in Canada, ${ }^{22}$ to $86 \%$ in Korea. ${ }^{23}$

There are plenty of tools to help with medication review and deprescribing such as the Beers criteria, ${ }^{24,25}$ START (screening tool to alert doctors to the right treatment), ${ }^{26}$ STOPP, ${ }^{27}$ ARMOR (assess, review, minimize, optimize, reassess), ${ }^{28} \mathrm{ARS}$ (anticholinergic risk scale), geriatric-palliative method, prescribing optimization method, ${ }^{29}$ and others. Nevertheless, these tools do not provide guidance or a practical approach to apply in daily clinical practice.

The Portuguese public health authority (Direção Geral da Saúde) has recently issued a recommendation concerning drug reconciliation. ${ }^{30}$ Despite these recommendations and tools, there are no guidelines in Portugal or Europe on how clinicians should deprescribe in elderly patients. The Canadian organization Bruyère Research Institute (deprescribing.org) and the Institut Universitaire de Gériatrie de Montréal (Centre de Reserche), provide guidelines and algorithms for deprescribing proton pump inhibitors (PPI), ${ }^{31,32}$ antihyperglycemic agents $(\mathrm{AH}),{ }^{33,34}$ antipsychotics $(\mathrm{AP})^{35,36}$ and benzodiazepines (BZ), ${ }^{37,38}$ that can easily be applied to daily clinical practice.

The aim of this study was to describe the prevalence of polypharmacy and inappropriate prescribing at admission and discharge in an internal medicine ward, according to deprescribing.org guidelines/algorithms.

\section{MATERIAL AND METHODS}

\section{Study design and population}

This is an observational, longitudinal, retrospective and descriptive study based on the population of an Internal Medicine ward in Hospital Fernando Fonseca (HFF), a public hospital in a Portuguese urban centre (population 600 000).

We used a convenience sample of patients aged 65 years or older who were discharged from an Internal Medicine ward, between January 1'st 2017, and July 31 ${ }^{\text {st }}, 2017$. Exclusion criteria included patients whose electronic charts were incomplete or unavailable, and patients who died before discharge.

\section{Data collection}

We collected demographic and clinical data from electronic charts regarding all patients involved. We considered the following age range for data analysis: [65 - 75], [76 - 85] and $\geq 86$ years old. Clinical variables included information on Barthel Index (BI), comorbidities, drugs, length of stay and readmission within 30 days after discharge (no matter the cause).

$\mathrm{BI}$ is an ordinal scale used to measure performance in daily living activities and it is validated to the Portuguese population. ${ }^{39}$ The patients' $\mathrm{BI}$ ratings were calculated according to information on nursing notes and records at hospital admission. Total possible scores range from 0 - 100 . A patient with a score under 20 is totally dependent, for a score between 20 - 39 is very dependent, 40 - 59 is partially dependent, $60-79$ is minimally dependent and if it is 80 100 the patient is independent.

Polypharmacy was defined as a use of five or more different medicines.

From the 15 most common chronic diseases, ${ }^{40}$ we evaluated data records regarding 6 that have major impact on life expectancy: hypertension (HTN), type 2 diabetes mellitus, cancer, chronic obstructive pulmonary disease (COPD), chronic kidney disease (CKD) and dementia.

We reviewed patients' medications from a medical database at hospital admission and at discharge according to deprescribing.org guidelines/algorithms of PPI, BZ, AP and $\mathrm{AH}$. We examined if patients were taking any anticoagulant (AC), PPI, BZ, AP and AH.

\section{Outcomes}

Primary outcome was defined as the prevalence of polypharmacy and inappropriate prescription at admission and discharge on this sample, according to deprescribing.org guidelines/algorithms.

Secondary outcomes were readmission rates within 30 days after discharge and its cause (no matter the cause). 


\section{Statistical analysis}

Discrete variables are presented as absolute frequencies with percentages, and continuous variables as mean \pm standard deviation if normally distributed, otherwise as median with interquartile range (IQR). Data was checked for normal distribution using Kolmogorov-Smirnov test.

Baseline characteristics of patients were compared using Fisher's exact test for categorical variables; parametric data was compared using Students' $t$-test; nonparametric data were evaluated using Mann-Whitney $U$ test.

Differences in the proportions of polypharmacy therapy at admission and at discharge were assessed using a tworelated groups McNemar test.

All statistical analyses were performed using version 22.0 of SPSS for Windows ${ }^{\circledR}$ (SPSS Inc., Chicago, IL, USA). All tests were bilateral and with a level of significance of $5 \%$.

\section{RESULTS}

\section{Study sample}

A total of 838 patients were initially evaluated in the internal medicine ward between January and July 2017. All patients were aged under 65 years old, and those who died during their stay in hospital, were excluded. A total of 483 patients were included in our final analysis (Fig. 1).

Mean age was $79.2 \pm 8.0$ years, and $42 \%$ of the patients were male.

Median length of stay was 11.3 (7.5 - 16.9) days, with a maximum hospitalisation of 67 days. Overall, $48 \%$ of our patients had HTN, 26\% had dementia, 24\% type 2 diabetes mellitus, 14\% COPD, 12\% cancer and CKD was present in $12 \%$ of our patients. Patients included in this study had a Barthel index median of 65.

Clinical and demographic characteristics are presented in Table 1.

\section{Drug use and polypharmacy}

The median number of medicines (among all taken drugs) at admission and at discharge was similar, 6 [4 - 8]. There were no significant differences in the proportion of patients under polypharmacy therapy at admission ( $\mathrm{n}=$ $361 ; 74.7 \%)$ and at discharge $(n=339 ; 70.2 \%), p=0.084$.
At both admission and discharge, polypharmacy was not significantly associated with age ( $p=0.689$ and $p=0.670$, respectively) or sex ( $p=0.596$ and $p=1.000$, respectively). In this study, PPI was the most prescribed drug (36\%), followed by $\mathrm{AH}$ (17\%), AP (15.9\%) and BZD (14.6\%).

Overall, polypharmacy was mainly driven by BZD, PPI and $\mathrm{AH}$ both at hospital admission and time of discharge (Table 1), with PPI being the most commonly prescribed drug in both instances.

Patients with polypharmacy at admission presented more frequently HTN (51.8\% vs $37.7 \% ; p=0.009)$, type 2 diabetes mellitus (28.8\% vs $11.5 \% ; p<0.001)$, COPD (16.3\% vs $6.6 \% ; p=0.006)$, and CKD (14.1\% vs $4.1 \% ; p$ $=0.002)$. On the other hand, patients with polypharmacy at discharge exhibited more frequently HTN (55.2\% vs $31.9 \%$; $p \leq 0.001)$ and COPD (15.9\% vs $9.0 \% ; p=0.045)$. Interestingly, dementia did not significantly affect the decision to use anticoagulants or not $(9.5 \%$ of patients with dementia were taking anticoagulants versus $11.5 \% ; p=0.621$ ).

Patients with polypharmacy at both admission and discharge did not have a significantly lower Barthel score in comparison with patients without polypharmacy (at admission, median score of 65 in patients with polypharmacy versus 55 without polypharmacy with $p=0.745$ and at discharge, median score of 60 in patients with polypharmacy versus 65 without polypharmacy with $p=0.623$ ).

\section{Inappropriate prescription}

The proportion of inappropriate prescription at discharge varied between $11.2 \%$ and $17.2 \%$, being higher for PPI and lower for BZD. AH represented $12 \%$ of inappropriate prescription at discharge and AP 13.5\%.

Unexpectedly, polypharmacy at admission and discharge did not significantly affect drug inappropriateness rate (Table 2).

\section{Patients' outcomes}

At admission, there were no significant differences in length of hospital stay between patients who had polypharmacy (11.3 days) and those who did not have polypharmacy (11.5 days), with a $p$ value of 0.614 (Fig. 2).

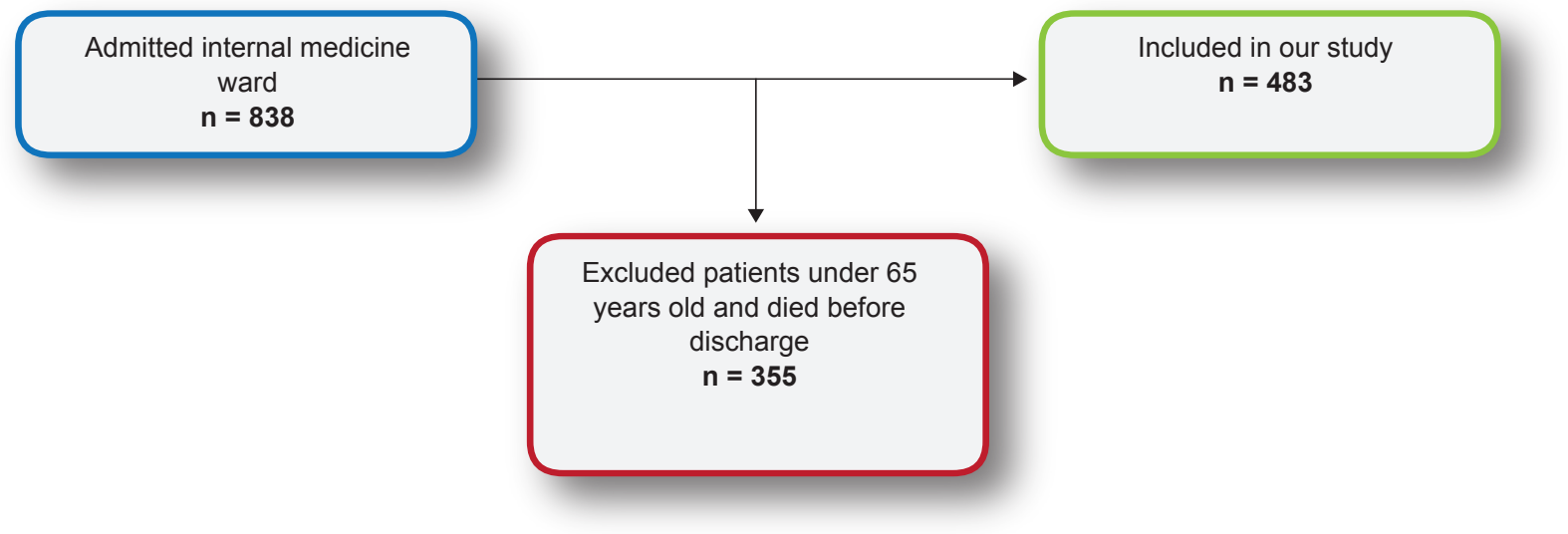

Figure 1 - Study population 
Table 1 - Clinical and demographic characteristics

\begin{tabular}{|c|c|c|c|c|c|c|}
\hline \multirow[b]{3}{*}{$\mathrm{n}(\%)$} & \multicolumn{2}{|c|}{ Admission } & \multicolumn{4}{|c|}{ Discharge } \\
\hline & $<5$ drugs & $\geq 5$ drugs & $p$ value & $<5$ drugs & $\geq 5$ drugs & $p$ value \\
\hline & $122(25.3)$ & $361(74.7)$ & & $144(29.8)$ & $339(70.2)$ & \\
\hline Age (years) (mean \pm SD) & $79.0 \pm 8.6$ & $79.3 \pm 7.8$ & 0.689 & $79.4 \pm 8.4$ & $79.1 \pm 7.8$ & 0.670 \\
\hline $65-75, \mathrm{n}(\%)$ & $43(35.2)$ & $116(32.1)$ & 0.578 & $50(34.7)$ & $109(32.2)$ & 0.598 \\
\hline $76-85, \mathrm{n}(\%)$ & $44(36.1)$ & $156(43.2)$ & 0.169 & $52(36.1)$ & $148(43.7)$ & 0.131 \\
\hline$\geq 86, \mathrm{n}(\%)$ & $32(26.2)$ & $87(24.1)$ & 0.629 & $41(28.5)$ & $78(23.0)$ & 0.206 \\
\hline \multicolumn{7}{|l|}{ Sex } \\
\hline Male, n (\%) & $54(44.3)$ & $149(41.3)$ & \multirow{2}{*}{0.596} & $60(41.7)$ & $143(42.2)$ & \multirow{2}{*}{1.000} \\
\hline Female, n (\%) & $68(55.7)$ & $212(58.7)$ & & $85(58.3)$ & $196(57.8)$ & \\
\hline \multicolumn{7}{|l|}{ Chronic conditions } \\
\hline Hypertension, n (\%) & $46(37.7)$ & $187(51.8)$ & 0.009 & $46(31.9)$ & $187(55.2)$ & $<0.001$ \\
\hline Dementia, n (\%) & $27(22.1)$ & $99(27.4)$ & 0.284 & $32(22.2)$ & $94(27.7)$ & 0.215 \\
\hline Diabetes mellitus, n (\%) & $14(11.5)$ & $104(28.8)$ & $<0.001$ & $27(18.8)$ & $91(26.8)$ & 0.064 \\
\hline Chronic obstructive pulmonary disease, $\mathrm{n}(\%)$ & $8(6.6)$ & $59(16.3)$ & 0.006 & $13(9.0)$ & $54(15.9)$ & 0.045 \\
\hline Cancer, n (\%) & $18(14.8)$ & $41(11.4)$ & 0.339 & $19(13.2)$ & $40(11.8)$ & 0.652 \\
\hline Chronic kidney disease, n (\%) & $5(4.1)$ & $51(14.1)$ & 0.002 & $12(8.3)$ & $44(13.0)$ & 0.164 \\
\hline Stage II, n (\%) & $1(0.8)$ & $13(3.6)$ & 0.207 & $4(2.8)$ & $10(2.9)$ & 1.000 \\
\hline Stage III, n (\%) & $2(1.6)$ & $29(8.0)$ & 0.010 & $7(4.9)$ & $24(7.1)$ & 0.423 \\
\hline Stage IV, n (\%) & $2(1.6)$ & $8(2.2)$ & 1.000 & $1(0.7)$ & $9(2.7)$ & 0.294 \\
\hline Stage V, n (\%) & 0 & $1(0.3)$ & 1.000 & 0 & $1(0.3)$ & 1.000 \\
\hline Barthel index, median (IQR) & $55(10-100)$ & $65(20-95)$ & 0.745 & $65(10-100)$ & $60(20-85)$ & 0.623 \\
\hline \multicolumn{7}{|l|}{ Medication } \\
\hline Anticoagulants, n (\%) & $9(7.4)$ & $44(12.2)$ & 0.180 & $13(9.0)$ & $40(11.8)$ & 0.429 \\
\hline BZD, n (\%) & $8(6.6)$ & $63(17.5)$ & 0.003 & $9(6.3)$ & $62(18.3)$ & $<0.001$ \\
\hline PPI, n (\%) & $33(27.0)$ & $141(39.1)$ & 0.017 & $29(20.1)$ & $145(42.8)$ & $<0.001$ \\
\hline $\mathrm{AH}, \mathrm{n}(\%)$ & $12(9.8)$ & $68(18.8)$ & 0.024 & $12(8.3)$ & $68(20.1)$ & 0.001 \\
\hline $\mathrm{AP}, \mathrm{n}(\%)$ & $19(15.6)$ & $58(16.1)$ & 1.000 & $16(11.1)$ & $61(18.0)$ & 0.077 \\
\hline
\end{tabular}

Independent samples Student's $t$-test was used to assess differences between normally distributed variables, whereas Mann-Whitney $U$-test was used to evaluate differences between non-parametric variables. Fisher's exact test was used to assess differences between discrete variables.

AH: antihyperglycemic; AP: antipsychotic; BZD: benzodiazepine; IQR: interquartile range; PPI: proton pump inhibitor; SD: standard deviation

At discharge, there were no significant differences in length of hospital stay between patients who had polypharmacy ( 11.3 days) and those who did not have polypharmacy (11.5 days), with a $p$-value of 0.345 (Fig. 3 ).

Total 30-day readmission rates were low, $2.5 \%(n=12)$. There were no significant differences in 30-day readmission rates in patients with polypharmacy versus no polypharmacy at admission (2.8\% vs $1.6 \%$, respectively; $p=0.739)$ or at discharge $(2.9 \%$ vs $1.4 \%$, respectively; $p=0.523)$.

\section{DISCUSSION}

There seems to be a slight decrease in polypharmacy, after the age of 85 , which corresponds to less than a quarter of this population. We believe this happens because there is a delay in the perception of need for deprescribing until patients get very old. However, in our study, polypharmacy was not significantly associated with age at admission and discharge, $(p=0.689$ and $p=0.670$, respectively).

In this study, polypharmacy was similar to what has been previously described in other studies ${ }^{41}$ focusing on patients' use of medicines on hospital admission and discharge.

In our study, PPI was the most prescribed drug, as seen in other studies. ${ }^{42,43} \mathrm{PPI}$ is often considered a safe and well tolerated drug, although it is not as innocuous as many physicians believe. If PPI is inappropriately prescribed or used for a long time, it can contribute to polypharmacy and other

Table 2 - Overall drug inappropriateness rate according to polypharmacy at admission and at discharge

\begin{tabular}{|c|c|c|c|c|c|c|}
\hline & \multicolumn{2}{|c|}{ Admission } & \multirow{2}{*}{$p$ value } & \multicolumn{2}{|c|}{ Discharge } & \multirow{2}{*}{$p$ value } \\
\hline & $<5$ drugs & $\geq 5$ drugs & & $<5$ drugs & $\geq 5$ drugs & \\
\hline Overall drug inappropriateness, $\mathrm{n}(\%)^{*}$ & $27(22.1)$ & $99(27.4)$ & 0.284 & $32(22.2)$ & $94(27.7)$ & 0.215 \\
\hline
\end{tabular}

* Overall drug inappropriateness defined as inappropriateness for at least one drug.

Fisher's exact test was used to assess differences between discrete variables 


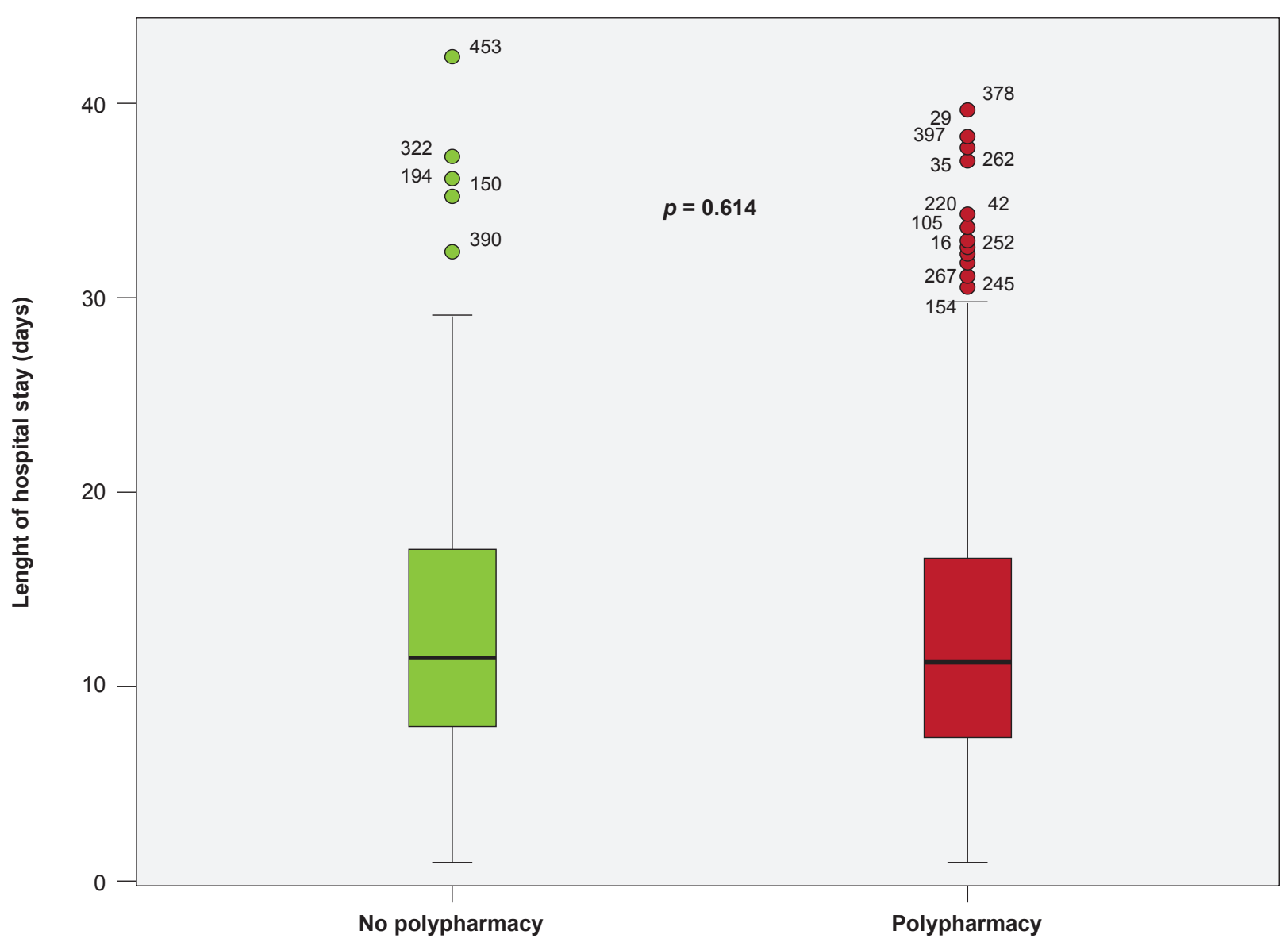

Figure 2 - Length of hospital stay (in days) according to polypharmacy at admission: in patients who did not have polypharmacy length was 11.3 days, and in those who have polypharmacy have a length of hospital stay of 11.5 days

issues such as aspiration pneumonia ${ }^{44}$ and dementia. ${ }^{45}$

The most prescribed PIM at hospital discharge was PPI, the least prescribed PIM was BZD, which is similar to other studies. $46-48$

In this study, $\mathrm{AH}$ treatment was prescribed in $80(17 \%)$ patients, and polypharmacy was present in $72 \%$ and $76 \%$ patients in hospital admission and discharge, respectively. This finding was similar to other studies. ${ }^{49,50}$ In 19 patients, there was no risk of hypoglycemia. However, we found it was present in 61 patients who were at risk, or potential risk, of hypoglycemia: 20 patients were taking insulin therapy (biphasic isophane insulin), 12 were taking sulphonylureas (gliclazide), 10 had dementia, eight had CKD, six had possible drug interaction (corticosteroids in five patients and hydrochlorothiazide in one patient) and 10 had low average life expectancy and frailty risk. Physicians should set individualized $\mathrm{A} 1 \mathrm{C}$ and blood glucose targets to decrease drug related hypoglycemia risk. In older age, frailty, and multiple comorbidities patients, A1C under $8.5 \%$ and blood glucose under $216 \mathrm{mg} / \mathrm{dL}$ may be acceptable. ${ }^{51}$

AP prescription was higher than expected according to other studies,,$^{52}$ probably because of bias on data collection due to incomplete patient records. BZD prescription was similar to other studies. ${ }^{53}$

In comparison to other studies, $\mathrm{BI}$ was higher in this study, meaning patients had a greater level of autonomy. ${ }^{54}$ However, patients with polypharmacy at admission or discharge did not have a significantly lower $\mathrm{Bl}$, in comparison with patients without polypharmacy (at admission, median score of 65 in patients with polypharmacy versus 55 without polypharmacy with $p=0.745$ and at discharge, median score of 60 in patients with polypharmacy versus 65 without polypharmacy with $p=0.623$ - Table 1 ). Results show that polypharmacy is linked to comorbidities but not to lower autonomy (as inferred from $\mathrm{BI}$ ). The higher $\mathrm{BI}$ is often related to shorter length of stay and polypharmacy side effects may only be present in the ambulatory setting. Given that our patients were less dependent than those who were included in other studies, we may conclude that deprescription is also delayed because of a false perception of less frailty.

Our study demonstrates a lower usage of inappropriate medications in older people discharged from an acute care hospital when compared to published data, ${ }^{55}$ although the criteria used to judge the appropriateness of prescribing were different.

Other studies, also regarding the elderly, show a very low prevalence (16\% and $25.5 \%$ ) of inappropriate prescribing in tertiary health care settings, ${ }^{56,57} 21.4 \%$ in primary care, ${ }^{58} 51.3 \%$ in acute hospital setting (Europe), ${ }^{41} 66 \%$ in a geriatric hospital ${ }^{55}$ and a higher prevalence $(82.6 \%)$ was 


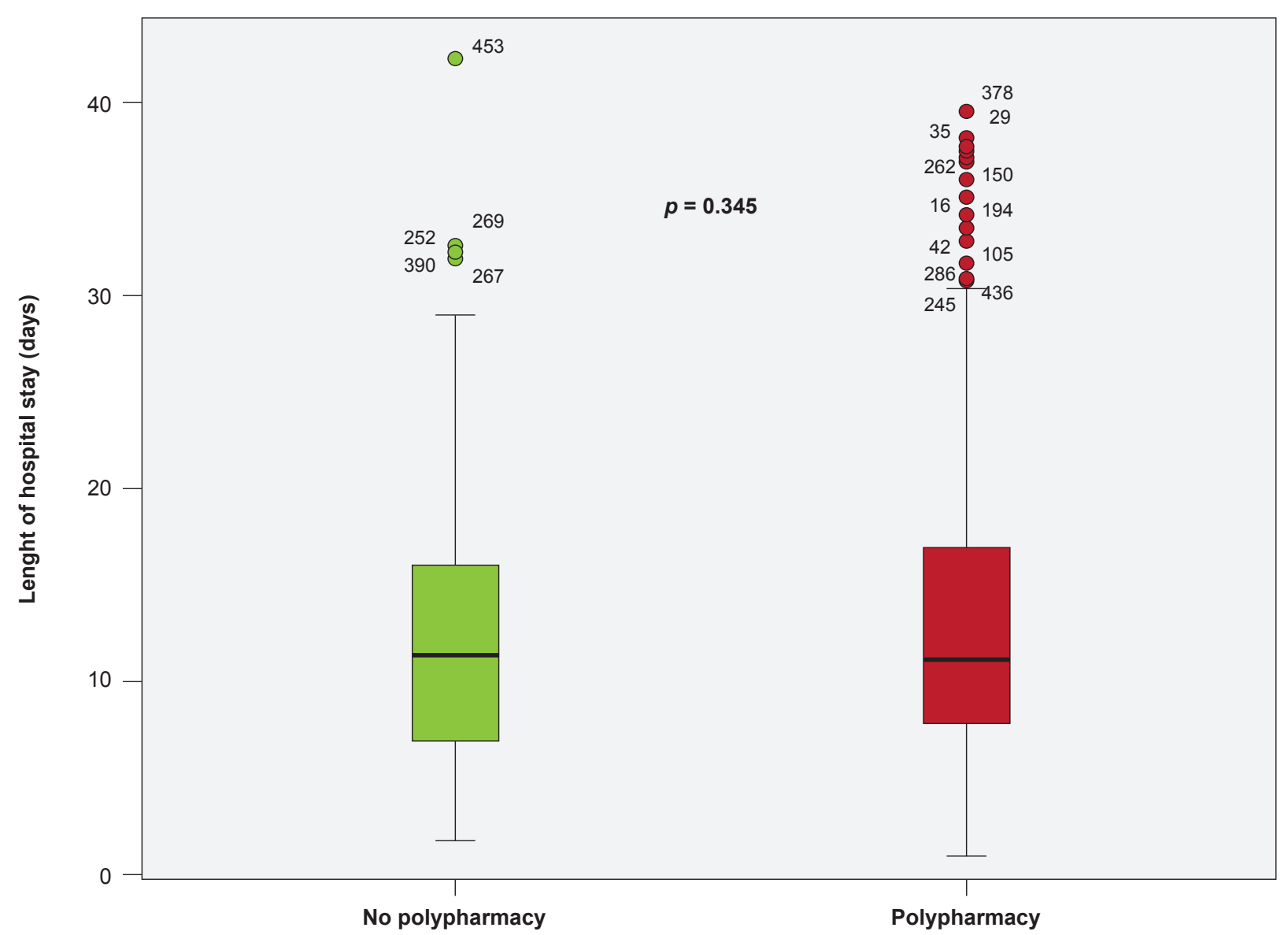

Figure 3 - Length of hospital stay (in days) according to polypharmacy at discharge: in patients who did not have polypharmacy length was 11.3 days, and in those who had polypharmacy had a length of hospital stay of 11.5 days

observed in a nursing care home..$^{59}$

There were no significant differences in length of hospital stay between patients who had polypharmacy and those who did not have polypharmacy, at both admission and discharge, which is not consistent with other studies. ${ }^{60}$

Older adults that use higher numbers of medicines, have increased adverse drug events and increased risk of adverse health outcomes. Decreasing polypharmacy and avoiding inappropriate prescribing therefore constitutes a major goal of care in this population. Clinicians should have an organized approach to systematically review the patient's therapeutic chart and eliminate unnecessary agents. They should explain to patients and their families why a given medicine may no longer be essential or beneficial according to the present clinical condition. The decision to maintain, reduce or discontinue a drug is based on a balance between its indication and effectiveness and possible harms of use, including actual or potential side effects, drug interactions, pill burden, and costs.

Admission in an internal medicine ward is an important moment to involve physicians, nurses and pharmacist in order to detect if there is any inappropriate prescribing and decrease drug related morbidity.

The present study is retrospective and data collection can cause bias due to the possibility of incomplete patient records. Drug dosage, regime undertaken and other comorbidities/drugs that weren't registered, could interact with the medicines evaluated. Presence of comorbidities was only ascertained during hospital stay; as such, eventual impact of new diagnoses or previous incorrect diagnoses were not taken into consideration in our analysis.

\section{CONCLUSION}

Polypharmacy is an important public health problem worldwide.

Decreasing polypharmacy and avoiding inappropriate medicines is a common goal of care in elderly people. Multidisciplinary team effort to do a regular prescription reconciliation and review is the golden rule to identify and reduce drug-related problems. There are tools to help the clinician improve prescribing and decrease high-risk/low-benefit medicines usage. However, a national guideline for deprescribing in Portugal is yet to be made. Future research is needed, focused on clinical, humanistic, and economic effect of deprescribing in the geriatric population.

Our study showed that polypharmacy is present in more than $70 \%$ of admitted elderly patients. Deprescribing is probably not a major concern for physicians yet, given the number of medications that remains unchanged between admission and discharge. Nevertheless, polypharmacy 
did not significantly affect the drug inappropriateness rate. PPI was the most common inappropriate drug at discharge $(17.2 \%)$, matching worldwide data.

\section{PROTECTION OF HUMAN AND ANIMAL}

The authors declare that the research procedures were performed according to the regulations of the institution's ethics committee and the Code of Ethics of the World Medical Association (Declaration of Helsinki).

\section{REFERENCES}

1. Pordata.pt. Base de dados Portugal Contemporâneo. Indicadores de envelhecimento. [accessed 2017 Nov 6]. Available from: http://www. pordata.pt/Portugal/Indicadores+de+envelhecimento-526.

2. Boyd C, Darer J, Boult C, Fried L, Boult L, Wu A. Clinical practice guidelines and quality of care for older patients with multiple comorbid diseases. JAMA. 2005;294:716.

3. Tinetti M, McAvay G, Chang S, Newman A, Fitzpatrick A, Fried T, et al. Contribution of multiple chronic conditions to universal health outcomes. J Am Geriatr Soc. 2011;59:1686-91.

4. World Health Organization. A glossary of terms for community health care and services for older persons. WHO. 2004 [accessed $2017 \mathrm{Nov}$ 8]. Available from: http://www.who.int/kobe_centre/ageing/ahp_vol5 glossary.pdf?ua=1

5. Carlson JE. Perils of polypharmacy: 10 steps to prudent prescribing. Geriatrics. 1996;51:26-35.

6. Linjakumpu T, Hartikainen S, Klaukka T, Veijola J, Kivelä S, Isoaho R. Use of medications and polypharmacy are increasing among the elderly. J Clin Epidemiol. 2002;55:809-17.

7. Hanlon JT, Schmader KE, Semla TP. Update of studies on drug-related problems in older adults. J Am Geriatr Soc. 2013;61:1365-8.

8. Veehof L, Stewart R, Haaijer-Ruskamp F, Jong BM. The development of polypharmacy. A longitudinal study. Fam Pract. 2000;17:261-7.

9. O'Connor M, Gallagher P, O'Mahony D. Inappropriate prescribing. Drugs Aging. 2012;29:437-52.

10. Price SD, Holman CD, Sanfilippo FM, Emery JD. Are older Western Australians exposed to potentially inappropriate medications according to the Beers criteria? A 13-year prevalence study. Australasian J Ageing. 2014;33:E39-48.

11. Wester K, Jönsson A, Spigset $O$, Druid H, Hägg S. Incidence of fatal adverse drug reactions: a population based study. $\mathrm{Br} \mathrm{J}$ Clin Pharmacol. 2008;65:573-9

12. Tinetti ME, Williams C. Falls, injuries due to falls, and the risk of admission to a nursing home. N Engl J Med. 1997;337:1279-84.

13. Meurer WJ, Potti TA, Kerber KA, Sasson C, Macy ML, West BT, et al. Potentially inappropriate medication utilization in the emergency department visits by older adults: analysis from a nationally representative sample. Acad Emerg Med. 2010;17:231-7.

14. Bowie MW, Slattum PW. Pharmacodynamics in older adults: a review. Am J Geriatr Pharmacother. 2007;5:263-303.

15. Haider SI, Johnell K, Weitoft GR, Thorslund M, Fastbom J. The influence of educational level on polypharmacy and inappropriate drug use: a register-based study of more than 600,000 older people. J Am Geriatr Soc. 2009;57:62-9.

16. Page AT, Clifford RM, Potter K, Schwartz D, Etherton-Beer CD. The feasibility and the effect of deprescribing in older adults on mortality and health: a systematic review. Brit J Clin Pharmacol. 2016;82:583-623.

17. Sousa S, Pires A, Conceição C, Nascimento T, Grenha A, Braz L. Polimedicação em doentes idosos: adesão à terapêutica. Rev Port Clin Geral. 2011;27:176-82.

18. Silva $P$, Luís $S$, Biscaia A. Polimedicação: um estudo de prevalência nos Centros de Saúde do Lumiar e de Queluz. Rev Port Clin Geral. 2004;20:323-36.

19. Instituto Superior de Estatística e Gestão de Informação. O consumo de medicamentos e a polimedicação em Portugal. Universidade Nova de Lisboa; 2010. [acessed 2018 Jun 10]; Available from http://www.novaims. unl.pt/docentes/vlobo/Publicacoes/3_29 SPE2010_polimidicacao.pdf.

20. Haider SI, Ansari Z, Vaughan L, Matters H, Emerson E. Prevalence and factors associated with polypharmacy in Victorian adults with intellectual

\section{CONFIDENTIALITY OF DATA}

The authors declare that they have followed the protocols of their work centre regarding the publication of data from patients.

\section{CONFLICT OF INTEREST}

No conflict of interest has been declared by any author.

\section{FUNDING}

No financial support was received by any author.

21. Haider SI, Johnell K, Thorslund M, Fastbom J. Trends in polypharmacy and potential drug-drug interactions across educational groups in elderly patients in Sweden for the period 1992-2002. Int J Clin Pharmacol Therap. 2007;45:643-53.

22. Ramage-Morin P. Medication use among senior Canadians. Health Rep. 2009;20:37-44

23. Kim H, Shin J, Kim M, Park B. Prevalence and predictors of polypharmacy among Korean elderly. PLoS One. 2014;9:e98043.

24. American Geriatrics Society 2012 Beers Criteria Update Expert Panel. American Geriatrics Society updated Beers Criteria for potentially inappropriate medication use in older adults. J Am Geriatr Soc.2012;60:616-31.

25. Aparasu R, Mort J. Inappropriate prescribing for the elderly: Beers criteria-based review. Ann Pharmacother. 2000;34:338-46.

26. Barry PJ, Gallagher P, Ryan C, O'mahony D. START (screening tool to alert doctors to the right treatment)-an evidence-based screening tool to detect prescribing omissions in elderly patients. Age Ageing 2007;36:632-8

27. Gallagher P, O'Mahony D. STOPP (screening tool of older persons potentially inappropriate prescriptions): application to acutely ill elderly patients and comparison with Beers' criteria. Age Ageing. 2008;37:6739.

28. Haque R. ARMOR: a tool to evaluate polypharmacy in elderly persons. Ann Long-Term Care. 2009;17:26-30.

29. Gokula M, Holmes HM. Tools to reduce polypharmacy. Clin Geriatr Med. 2012;28:323-41.

30. Direção Geral da Saúde. Norma nº 018/2016 de 30/12/2016. [acessed 2017 Nov 8]. Available from: https://www.dgs.pt/directrizes-da-dgs/ normas-e-circulares-normativas/norma-n-0182016-de-30122016.aspx.

31. Farrell B, Pottie K, Thompson W, Boghossian T, Pizzola L, Rashid $\mathrm{F}$, et al. Deprescribing proton pump inhibitors. Can J Hosp Pharm. 2017;63:354-64.

32. Bruyère Research Institute. Proton Pump Inhibitor (PPI) Deprescribing Algorithm, 2016. [accessed 2017 Nov 6]. Available from: http://www. open-pharmacy-research.ca/wp-content/uploads/ppi-deprescribingalgorithm-cc.pdf.

33. Farrell B, Black C, Thompson W, McCarthy L, Rojas-Fernandez C, Lochnan $\mathrm{H}$, et al. Deprescribing antihyperglycemic agents in older persons. Can Fam Physician. 2017;63:832-43.

34. Bruyère Research Institute. Antihyperglycemics deprescribing algorithm, 2016. [accessed 2017 Nov 6]. Available from: http://www. open-pharmacy-research.ca/wp-content/uploads/ppi-deprescribingalgorithm-cc.pdf.

35. Farrell B, Hogel M, Graham L, Lemay G, McCarthy L, Raman-Wilms L, et al. Deprescribing antipsychotics for behavioural and psychological symptoms of dementia and insomnia. Can Fam Physician. 2018;64:1727

36. Bruyère Research Institute. Antipsychotic (AP) deprescribing algorithm, 2017. [accessed 2017 Nov 6]. Available from: http://www. open-pharmacy-research.ca/wp-content/uploads/antipsychoticdeprescribing-algorithm.pdf.

37. Pottie K, Thompson W, Davies S, Grenier J, Sadowski C, Welch V, et al. Deprescribing benzodiazepine receptor agonists. Can Fam Physician. 2018;64:339-51.

38. Bruyère Research Institute. Benzodiazepine \& Z-Drug (BZRA) deprescribing algorithm, 2016. [accessed 2017 Nov 6]. Available from: http://www.open-pharmacy-research.ca/wp-content/uploads/ 
deprescribing-algorithm-benzodiazepines.pdf.

39. Araújo F, Ribeiro J, Oliveira A, Pinto C. Validação do índice de Barthel numa amostra de idosos não institucionalizados. Rev Port Saúde Pública. 2007;25:59-66.

40. Centers for Disease Control and Prevention. Chronic diseases: the leading causes of death and disability in the United States. [Accessed Nov 10 2017]. Available from: https://www.cdc.gov/chronicdisease/ overview/index.htm.

41. Gallagher P, Lang P, Cherubini A, Topinková E, Cruz-Jentoft A, Montero Errasquín B, et al. Prevalence of potentially inappropriate prescribing in an acutely ill population of older patients admitted to six European hospitals. Eur J Clin Pharmacol. 2011;67:1175-88.

42. McDonald E, Jones J, Green L, Jayaraman D, Lee T. Reduction of inappropriate exit prescriptions for proton pump inhibitors: a before-after study using education paired with a web-based quality-improvement tool. J Hospital Med. 2015;10:281-6.

43. Wermeling M, Himmel W, Behrens G, Ahrens, D. Why do GPs continue inappropriate hospital prescriptions of proton pump inhibitors? A qualitative study. Eur J General Practice. 2013;20:174-80.

44. Fohl AL, Regal RE. Proton pump inhibitor-associated pneumonia: Not a breath of fresh air after all? World J Gastrointest Pharmacol Ther. 2011;2:17.

45. Gomm W, von Holt K, Thomé F, Broich K, Maier W, Fink A, et al. Association of proton pump inhibitors with risk of dementia: a pharmacoepidemiological claims data analysis. JAMA neurol. 2016;73:410-6.

46. Hamilton H, Gallagher P, Ryan C, Byrne S, O'Mahony D. Potentially inappropriate medications defined by STOPP criteria and the risk of adverse drug events in older hospitalized patients. Arch Intern Med. 2011;171:1013-9.

47. Stafford AC, Alswayan MS, Tenni PC. Inappropriate prescribing in older residents of Australian care homes. J Clin Pharm Ther. 2011;36:33-44.

48. Hanlon JT, Artz MB, Pieper CF, Lindblad Cl, Sloane RJ, Ruby CM, et al. Inappropriate medication use among frail elderly inpatients. Ann Pharmacother. 2004;38:9-14.

49. Huang ES, Gorawara-Bhat R, Chin MH. Self-reported goals of older patients with type 2 diabetes mellitus. J Am Geriatric Soc. 2005;53:306-
11.

50. Brown SE, Meltzer DO, Chin MH, Hung ES. Perceptions of quality of life effects of diabetes treatments among vulnerable and non-vulnerable older patients. J Am Geriatr Soc. 2008;56:1183-90.

51. Laubscher T, Regier L, Bareha J. Diabetes in the frail elderly. Can Fam Physician. 2012;58:543-46.

52. Saiyed S, Saiyed S, Tawiah P, Eskildsen M. Reducing inappropriate use of antipsychotics in long term care residents. J Am Med Directors Associat. 2014;15:B22.

53. Tannenbaum C. Inappropriate benzodiazepine use in elderly patients and its reduction. J Psychiatr Neurosci. 2015;40:E27-8.

54. Dalleur O, Spinewine A, Henrard S, Losseau C, Speybroeck N, Boland $B$. Inappropriate prescribing and related hospital admissions in frail older persons according to the STOPP and START criteria. Drugs Aging. 2012;29:829-37.

55. Marzi MM, Diruscio AV, Nunez HM, Pires SM, Quaglia BN. Analysis of medication prescription in an Argentinian geriatric Hospital. Rev Med Chil. 2013;141:194-201.

56. Undela K, Bansal D, D'Cruz S, Sachdev A, Tiwari P. Prevalence and determinants of use of potentially inappropriate medications in elderly inpatients: a prospective study in a tertiary healthcare setting. Geriatr Gerontol Int. 2014;14:251-8.

57. Fadare JO, Agboola SM, Opeke OA, Alabi RA. Prescription pattern and prevalence of potentially inappropriate medications among elderly patients in a Nigerian rural tertiary hospital. Ther Clin Risk Manag. 2013;6:115-20.

58. Ryan C, O'Mahony D, Kennedy J, Weedle P, Byrne S. Potentially inappropriate prescribing in an Irish elderly population in primary care. Br J Clin Pharmacol. 2009;68:936-47.

59. Vieira de Lima TJ, Garbin CA, Garbin AJ, Sumida DH, Saliba O Potentially inappropriate medications used by the elderly: prevalence and risk factors in Brazilian care homes. BMC Geriatr. 2013;13:52.

60. Harugeri A, Joseph J, Parthasarathi G, Ramesh M, Guido S. Potentially inappropriate medication use in elderly patients: a study of prevalence and predictors in two teaching hospitals. J Postgrad Med. 2010;56:18691. 